\title{
ALGODÃO ORGÂNICO: POSSIBILIDADE SUSTENTÁVEL NO SETOR AGRÍCOLA
}

\author{
Gabriela Helena Pinê Américo ${ }^{1}$
}

\section{Juliana Heloisa Pinê Américo²}

\section{Enes Furlani Júnior ${ }^{3}$}

RESUMO: A produção de algodão orgânico exige um manejo mais intensivo e inovador que a produção convencional, e nos últimos anos, vem ganhando grande importância no cenário agrícola nacional e internacional, pois evitam danos ao meio ambiente. $O$ algodão para ser considerado orgânico precisa ser certificado. A certificação é um instrumento de garantia de que o algodão orgânico foi produzido dentro de um conjunto mínimo de normas. Assim, é necessário o estudo de alternativas que substituam a utilização de agrotóxicos na cultura do algodoeiro por maneiras sustentáveis de modo a preservar o meio ambiente e a utilização da produção de algodão orgânico no Brasil. Dessa forma, o objetivo deste trabalho foi discutir as alternativas sustentáveis na produção de algodão através de uma revisão bibliográfica. Os fertilizantes são os maiores desafios da agricultura orgânica, sendo necessário o conhecimento aprimorado dos ciclos dos nutrientes para se adotar as práticas de manejo mais adequadas. Para controlar os ataques de pragas e doenças no algodoeiro que é um dos grandes problemas do intenso uso de defensivos agrícolas tem-se como alternativa o controle biológico através de biopesticidas e bioagentes. Outras formas de evitar a aplicação de agrotóxicos é optar por variedade de algodão resistente a essas pragas chaves da cultura e rotação de cultura. Com todas essas práticas reunidas, o desenvolvimento sustentável é alcançado, ou seja, consegue-se o benefício social, o respeito ao meio ambiente e a viabilidade econômica.

Palavras-chave: Agrotóxicos. Fertilizantes. Sustentabilidade.

\footnotetext{
${ }^{1}$ Mestranda do Programa de Pós-graduação em Sistema de produção - Faculdades de Engenharia de llha Solteira (UNESP). E-mail: americo.gabi@gmail.com

${ }^{2}$ Doutoranda em Aquicultura, Centro de Aquicultura da UNESP. E-mail: americo.ju@gmail.com

${ }^{3}$ Prof. Titular da Faculdade de Engenharia de llha Solteira (UNESP).
} 


\section{INTRODUÇÃO}

O algodoeiro é uma das culturas que possui extrema importância mundial, quer pelo seu valor monetário da produção, multiplicidade de produtos que dela se originam e a popularidade de que estes gozam. São cultivados aproximadamente 31,1 milhões de hectares de algodão em todo o mundo, sendo o Brasil responsável por 1.402 mil hectares, o que coloca o país entre os seis maiores produtores do mundo (CONAB, 2012).

O algodão orgânico é cultivado dentro de um sistema que fomenta a atividade biológica, estimula a sustentabilidade e exige um manejo diferente do sistema de produção convencional. Os sistemas orgânicos dependem basicamente de insumos naturais, contribuindo para a saúde do solo e dos seres humanos. Fertilizantes orgânicos são todos aqueles produtos naturais que, adicionados ao solo, tem como objetivo, produzir húmus e contribuir para manter ou elevar o equilíbrio húmico dos solos. A eficiência desses fertilizantes na produtividade final depende de alguns fatores que devem ser considerados, como: qualidade e quantidade de aplicação, épocas e condições de utilização, métodos de aplicação, adequabilidade aos sistemas agrícolas e custo relativo de sua utilização (CAVALCANTI, 1998).

Durante as décadas de sessenta, setenta e oitenta o Brasil encontrava-se entre os maiores produtores e exportadores mundiais de algodão. Entretanto, com a chegada do bicudo do algodoeiro, muitas plantações foram dizimadas. $\mathrm{O}$ algodão então surgiu como alternativa de rotação com a soja, contudo era preciso alcançar melhores níveis de produtividade. Investimentos em qualidade e pesquisas fizeram com que o setor crescesse. A ampliação do mercado de exportação fez com que o país, em menos de oito anos, deixasse de ser o segundo maior importador para integrar a lista dos maiores exportadores. A qualidade da fibra, a produtividade e o clima favorável são considerados pontos chaves para o desenvolvimento da cultura (MARQUES, 2008).

Com o surgimento dessa praga no Brasil, o plantio de algodão recebeu ainda mais aplicações de produtos químicos sintéticos, tornando-se então um dos grandes desafios enfrentados atualmente pelos pesquisadores brasileiros em desenvolver pesquisas para a produção de algodão orgânico, ou seja, sem o uso de agrotóxicos. (EMBRAPA, 2010). 
Assim é necessário o estudo de alternativas que substituam a utilização de agrotóxicos na cultura do algodoeiro por maneiras sustentáveis de modo a preservar o meio ambiente e a utilização da produção de algodão orgânico no Brasil. Dessa forma, o objetivo deste trabalho foi discutir as alternativas sustentáveis na produção de algodão através de uma revisão bibliográfica.

\section{DESENVOLVIMENTO}

Atualmente, existe uma grande exigência de indicadores de desenvolvimento sustentável, já que este passa a ser o novo paradigma de desenvolvimento. $O$ velho padrão de desenvolvimento e crescimento não poderia mais ser suportado pelo planeta terra, seja a longo ou mesmo a curtos prazos.

O algodão orgânico aparece como uma cultura alternativa, que busca ser ambientalmente sustentável e minimiza qualquer efeito negativo sobre a natureza. Além disto, ganha mercado, à medida que os consumidores se tornam mais conscientes dos limites do meio ambiente em suportar o processo de crescimento das sociedades humanas, com todos os seus pontos negativos, como a poluição ambiental, a geração de resíduos sólidos, a contaminação dos alimentos e matérias-primas, a diminuição da biodiversidade e dos recursos naturais. (PEREIRA, 2002).

O algodão para ser considerado orgânico precisa ser certificado. A certificação é um instrumento de garantia de que o algodão orgânico foi produzido dentro de um conjunto mínimo de normas. Para manter a condição de orgânico até o produto final é necessário que toda a cadeia de produção seja inspecionada e certificada como orgânica (THE ICAC, 1993).

As condições de cultivo devem obedecer a práticas orgânicas, assim como as etapas subsequentes, como o beneficiamento, fiação e tecelagem, também devem ser certificadas como orgânicas. A ausência dos chamados "insumos modernos" nos sistemas orgânicos de produção faz com que se veicule a ideia preconceituosa de que são sistemas "atrasados", ou mesmo um "retorno ao passado". Ao contrário, a produção orgânica moderna de algodão requer um manejo muito mais intensivo e inovador do que a forma convencional de se produzir à fibra (THE ICAC, 1993). 
Existem diversos sistemas de produção de algodão orgânico, desde os que utilizam muitas tecnologias, como os observados nos Estados Unidos, até os sistemas que utilizam pouca tecnologia, como os que ocorrem no Brasil (SOUZA, 1998).

Uma das alternativas utilizadas no Brasil é o algodão colorido de fibra marrom que tem apresentado excelente potencial de cultivo no semi-árido nordestino, onde as condições edafoclimáticas possibilitam a sua exploração sem o uso de defensivos agrícolas (SANTANA et al., 1999), condição requerida nos sistemas orgânicos. Segundo Buschle-Diller et al., 1998, a presença de pigmentos naturais em suas fibras elimina a necessidade de tintura com corantes sintéticos, diminuindo os impactos ambientais, porém o algodão colorido também apresenta desvantagens. Pode contaminar algodões brancos durante o cultivo e o beneficiamento deve ser realizado separadamente. Sua produtividade é cerca de $10 \%$ menor do que as variedades brancas comerciais e a pluma colorida nem sempre alcança as exigências da fiação industrial. Além disso, são poucas as opções de cores e há problemas de comercialização, dada a grande incerteza que ainda existe nesse mercado (THE ICAC, 1993).

Os fertilizantes são os maiores desafios da agricultura orgânica, sendo necessário o conhecimento aprimorado dos ciclos dos nutrientes para se adotar as práticas de manejo mais adequadas. A eficiência no fluxo de nutrientes que estão imobilizados para a solução do solo, é essencial para a manutenção da fertilidade nos sistemas orgânicos (KLONSKY et al., 1996).

Bulluck et al. (2002) afirmam que compostos orgânicos usados como melhoradores alternativos da fertilidade do solo, podem resultar em incremento da matéria orgânica e atividade biológica do solo. Conforme os resultados desses autores, condicionadores orgânicos de solo como o esterco bovino e o composto de caroço de algodão, podem ser superiores aos fertilizantes sintéticos, por melhorarem os atributos biológicos, físicos e químicos do solo, incrementando a produtividade das plantas. Para Bulluck \& Ristaino (2002), o uso de melhoradores alternativos do solo pode resultar em melhoria da qualidade do solo e no controle de doenças de plantas.

Uma alternativa para controlar os ataques de pragas e doenças no algodoeiro é o controle biológico através de biopesticidas, como é o caso das cepas do Bacillus thurigiensis, bactéria aeróbica que apresenta um efetivo controle de várias pragas como o curuquerê (Alabama argillscea) e a lagarta da maçã (Hellothis virescens). 
A utilização de bioagentes também é uma opção sustentável, estes bioagentes são parasitoides ou predadores como joaninhas (Cycloneda sanguinea e Cetatomegilla maculata) que se alimentam de pulgões (BELLOTTI, 1992).

A principal praga da cultura do algodoeiro é o bicudo (Anthonomus grandis) que pode causar perdas na lavoura de até $70 \%$, para evitar prejuízos ao meio ambiente recomenda-se recolher todos os botões que caírem ao solo e destruí-los, evitando que a população da praga aumente através de seus descendentes (EMBRAPA, 2010).

Segundo Embrapa (2010), o uso de um inseticida natural à base de caolim - um pó de rocha de cor branca, composto por silicato de alumínio também recomendado. Após a pulverização do caolim diluído em água, a planta fica tingida de branco, tornando-se irreconhecível para o bicudo, além de atrapalhar a sua movimentação e alimentação, pois as partículas focam aderidas ao corpo do inseto. As aplicações com caolim devem ser realizadas sempre que $5 \%$ das plantas de algodão apresentarem botões florais danificados pelo bicudo (EMBRAPA, 2010).

Além do controle biológico outra forma de evitar a aplicação de agrotóxicos é optar por variedade de algodão resistente a essas pragas chaves da cultura. Essa prática representa a medida de controle mais eficiente e econômica e tem sido um dos pressupostos do programa de melhoramento genético do algodoeiro; entretanto, devido as condições desfavoráveis à doença no semi-árido, mesmo cultivares com resistência ou suscetibilidade moderadas, tais como a BRS 201 e BRS $1878 \mathrm{H}$, podem ser recomendadas para o plantio nesta região (EMBRAPA, 2003).

A rotação de cultura é um método bem utilizado com objetivo de manipular o agroecossistema para torná-lo desfavorável ao desenvolvimento das pragas, e ao mesmo tempo favorável ao desenvolvimento dos seus inimigos naturais. A rotação na cultura do algodão é utilizada como estratégia de convivência com as pragas da cultura, principalmente no que diz respeito ao bicudo e a lagarta rosada (BELTRÃO, 1999)

\section{CONSIDERAÇÕES FINAIS}

Par ampliar a produtividade da cultura algodoeira em sistema orgânico, a utilização de práticas como a adição de adubos orgânicos, controle biológico e rotação de culturas proporcionam a melhoria das qualidades físicas e químicas do solo além de diminuir as 
infestações de pragas e doenças. O uso de variedades resistentes é uma excelente alternativa, pois além de evitar gastos com defensivos agrícolas controla 0 ataque de pagas e a manifestação de doenças.

Com todas essas práticas reunidas, o desenvolvimento sustentável é alcançado, ou seja, consegue-se o benefício social, o respeito ao meio ambiente e a viabilidade econômica.

\section{REFERÊNCIAS}

BELTRÃO, N. E. de M. O Agronegócio do algodão no Brasil . Brasília-DF. EMBRAPA Algodão: Embrapa Comunicação para Transferência de Tecnologias, v.1, 1999. 1023p.

BELLOTTI, A. C. Controle biológico no contexto da agricultura sustentável. In: Simpósio de controle biológico, 3. Aguas de Lindoia. Anais...Jaguariuna: EMBRAPA-CNPDA, p. 25, 1992.

BULLUCK, L.R.; RISTAINO, J.B. Synthetic and organic amendments affect southern blight, soil microbial communities and yield of processing tomatoes. Phytopathology, St. Paul, v.92, p.181-189, 2002.

BULLUCK, L.R.; BROSIUS, M..G.; EVANYLO, K.; RISTAINO, J.B. Organic and synthetic fertility amendments influence soil microbial, physical and chemical properties on organic and conventional farms. Applied Soil Ecology, Amsterdam, v.19, n.2, p.147-160, 2002.

BUSCHLE-DILLER, G.; KNIGHT, C.; PERSON, A.; FOX, S.V. Naturally colored cottons shade changes upon wet treatments. In. Beltwide Cotton Conference, 1998, Memphis, Proceedings....Memphis: National Cotton Council of America, 1998, p.730-732.

CAVALCANTI, J de A. Recomendações de adubação para o estado de Pernambuco, 2. ed, $2^{a}$ aproximação. Recife: IPA, 1998. 198 p.

COMPANHIA NACIONAL DE ABASTECIMENTO. Safras/algodão, Brasília, 2012. Disponível em: <http://www.conab.gov.br>. Acesso: 27 set. 2013.

EMBRAPA. Pesquisa estuda a produção do algodão orgânico. Brasília: Embrapa Algodão, 2003. 
EMBRAPA. Cultura do Algodão Herbáceo na Agricultura Familiar. Brasília: Embrapa Algodão, 2010.

KLONSKY, K.; TOURTE, L.; SWEZEY, S. Production practices and economic performance for organic cotton northern San Joaquin Valley-1995. In. Beltwide Cotton Conference, Memphis, Proceedings... Memphis: National Cotton Council of America, 1996, p.172-174.

MARQUES, F. Investimentos no setor fez com que o país se tornasse segundo maior exportador mundial de algodão. Disponível em $<$ http://www.algodao.agr.br/cms/index.php?option=com content\&task=view\&id=1624\&lte mid=96> Acesso: 25 set. 2013.

PEREIRA, N. L.; VIANA, LIMA, M. O.; KHAN, A. S.; MAYORGA, R. D.. Análise da sustentabilidade da produção do algodão orgânico: estudo de caso do município de Tauá. In: congresso brasileiro de economia e sociologia rural, 40, 2002, Passo Fundo-RS. Anais... Brasília-DF: SOBER, 2002. v. 1. p. 1-19

SANTANA, J. C. F. DE.; FREIRE, E. C.; COSTA, J. N. DA.; OLIVEIRA. A. M.; GUSMAO, J. L.; SILVA, I. M. DA. Novas linhagens e cultivares dos algodoeiros arbóreos e herbáceos para o Nordeste. In: Congresso Nacional de Técnicos. Anais.. 15, Natal. p.10, 1992

SOUZA, M. C. M. Algodão orgânico: o papel das organizações na coordenação e diferenciação do sistema agroindustrial do algodão. São Paulo: USP/FEA, 1998. 187 p. Dissertação de Mestrado - Universidade de São Paulo.

THE ICAC RECORDER: International Conference on Organic Cotton. The ICAC Recorder, v. 11, n. 4, 1993. p.11-14. 